\title{
RELATIONSHIP BETWEEN FLATFOOT AND Q ANGLE IN MALE SECONDARY SCHOOL STUDENT
}

\author{
Mohamed N. AlKhouli *1, Anees S. Ghait ${ }^{2}$, Amr A.Abogazya ${ }^{3}$.
}

${ }^{* 1}$ Department of Growth\& Development disorders and its Surgery in Pediatric, Delta University for Science and Technology, Egypt.

${ }^{2}$ Department of Biomechanics, Kafrelsheikh University, Egypt.

${ }^{3}$ Department of Basic Science, Faculty of Physical Therapy, Kafrelsheikh University, Egypt.

\section{ABSTRACT}

Background: A high percentage of young children present with flatfeet. Flat foot in children and adolescents, as a consequence of various factors such as hypo kinesis, obesity or hereditary factors, represents a current problem.

The purpose of this study was to determine relationship between flatfoot and Q Angle in male secondary school students from standing position.

Subjects and Methods: Forty participants were included in this study divided into two groups, group A (20 normal healthy male secondary school students) while group B (20 male secondary school students are suffering from flat foot ); (age range 16-18 years, weight $71.5 \pm 14.4 \mathrm{~kg}$, height $171.5 \pm 6.1 \mathrm{~cm}$, were selected randomly.

Results: Results indicated that there was statistically significant increase in participant's quadriceps-angle of the right or left knees $(P<0.05)$ in group $B$ (male secondary school students are suffering from flat foot) during standing position.

Conclusion: There were no statistically significant changes in the participant's quadriceps-angle between the right and left knees ( $P>0.05$ ) either in group $B$ (male secondary school students suffering from flat foot) or in group A (normal healthy male secondary school students). With regard to this study results, we concluded that, flat foot deformity may resulted in increasing the value of $Q$ angle.

KEY WORDS: Q Angle, Flat foot deformity, Secondary school students, Standing position, Radiography.

Address for correspondence: Dr. Mohamed N. AlKhouli, Department of Growth\& Development disorders and its Surgery in Pediatric, Delta University for Science and Technology, Egypt.

E-Mail: dr_alkhoulim@Yahoo.com

\section{Access this Article online}

Quick Response code

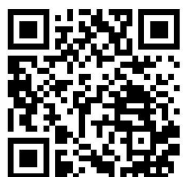

DOI: $10.16965 /$ ijpr.2017.232
International Journal of Physiotherapy and Research

ISSN 2321- 1822

www.ijmhr.org/ijpr.html

$\begin{array}{ll}\text { Received: 08-09-2017 } & \text { Accepted: 09-10-2017 } \\ \text { Peer Review: 09-09-2017 } & \text { Published (O): 11-11-2017 } \\ \text { Revised: None } & \text { Published (P): 11-12-2017 }\end{array}$

Received: 08-09-2017

Revised: None

energy-storing mechanisms [2,3].

Muscles of the foot provide secondary support by maintaining the arch during dynamic tasks [1].

Flatfeet are often a complex disorder, with diverse symptoms and varying degrees of deformity and disability. There are several types of flatfoot, all of which have one characteristic 
in common-partial or total loss of the arch [2, 4]. Flat feet in children are normal when they first begin to stand because as they try to keep balance and grip with the feet for support, they tend to spread apart in a wide stance and the soles turn outward $[5,6]$.

Many different factors can contribute to the development of flat feet. These include overweight, the types of shoes a child wears, a child's sitting or sleeping positions, compensation for other abnormalities further up the leg, or more severe factors such as rupture of ligaments or tendons in the foot [4].

Repeated excessive loading may stretch ligaments beyond their elastic limit, damaging soft tissues and increasing the risk of foot discomfort and subsequent development of foot pathologies [1].

Excessive foot pronation which occurs in flat foot deformity is characterized by flattening of medial arch and hypermobile midfoot but may also place greater demands on neuromuscular system to stabilize the foot and maintain upright stance.

Poor foot position sense is thought to hinder accommodation between the plantar surface of the foot and the support surface, thus requiring postural adjustments more proximally to maintain upright posture and balance $[10,11]$.

Although investigators found static and dynamic balance to be adversely affected by changes in peripheral input secondary to joint injury and changes in the stability of the surface on which one is standing, far less attention has been focused on whether more subtle alterations in the surface, stability, or peripheral input of the support foot may also affect balance in those with different foot types $[7,9]$.

The deleterious effect of flat foot on the mechanics of human body results from the manifestation of abnormal foot mechanics which include abnormal foot pronation and diminished foot arches (7).

Therefore, this study aims to compare Q-angle between normal and flat foot deformity in secondary school students.

\section{SUBJECTS AND METHODS}

Forty participants were included in this study divided into two groups, group A (20 normal healthy male secondary school students) while group B (20 male secondary school students are suffering from flat foot ); (age range 16-18 years, weight $71.5 \pm 14.4 \mathrm{~kg}$, height $171.5 \pm 6.1 \mathrm{~cm}$, were selected randomly.

The participants in the present study were selected from a population of secondary school students in Tanta and Mansoura cities.

All subjects participated voluntarily after being informed about the purpose of the study and having signed a written informed consent. Prior to selection, each individual underwent a thorough clinical assessment and was questioned about past medical history.

Subjects with postural deviations, such as leg length discrepancy, knee joint osteoarthritis, recurvatum knees, ankle joint deformities, muscle shortening, kyphosis and/or scoliosis, past surgery, injury of the lower limbs or patellofemoral pain syndrome, thyroid dysfunction or rheumatic conditions, obesity, dominant left leg, patellar luxation or subluxation, clinical evidence of meniscal injury, ligamentous instability, patellar tendinitis, lower back pain, sciatica, other condition that may interfere with the data collection were excluded from the experimental procedure.

The participants were positioned standing with barefoot, their knees in total extension and each patient were asked to keep her lower limbs in a relaxing status and no trunk - forward or posterior swing was permitted.

The participants were urged to maintain a fixed posture during every test procedure to maintain consistent measurements.

Afterwards, the same technician took radiographs (A 500 mm A G3 Model, Macrotec ${ }^{\circledR}$ ) in anteroposterior positioning using radiological 35 $x 91 \mathrm{~cm}$ film, comprising a portion of the hip 15 $\mathrm{cm}$ below the previously market TAT using a lead film $(4 \mathrm{~cm} 2)$ fixed on the skin with adhesive tape, in order to facilitate the visualization of the TAT after revealing the film (a Kodak ${ }^{\circledR}$ film).

The $Q$ angle is formed by the crossing of two imaginary lines: the first line is formed by the anterosuperior iliac spine (ASIS) to the midpoint of the patella, and the second line is formed by the tibial tuberosity to the midpoint of patella 
[12]. The $Q$ angle was traced and measured for the right and left knee by the same researcher using a conventional rule, a pen, and protractor to prevent study error (Figure 1).

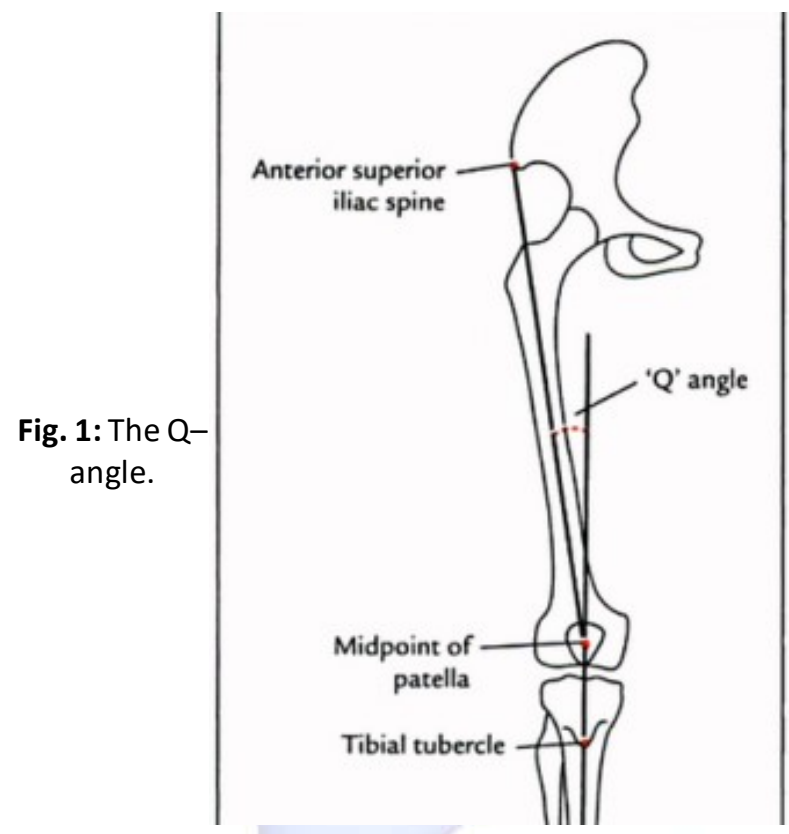

The design of this study was a case control study. Statistical analysis involved the calculation of the means and standard deviations for each of the variables measured. Differences between the values of the $Q$ angle between the participants were assessed using the student-t test. A P-value of $<0.05$ was taken to represent statistical significance. Data analysis was performed using SPSS software version 16.

\section{RESULTS AND DISCUSSION}

All data had been collected and statistically analyzed and presented under the following headings:

General Characteristics of the Participants: Forty participants were included in this study divided into two groups, group A (20 normal healthy male secondary school students) while group B (20 male secondary school students are suffering from flat foot ); (age range 16 - 18 years, weight $71.5 \pm 14.4 \mathrm{~kg}$, height $171.5 \pm 6.1 \mathrm{~cm}$, were selected randomly .

Q - Angle

Right Knee: There was statistically significant increase in participant's $Q$-angle $(P=0.05)$, as the mean value of $Q$-angle was $16.140_{ \pm} 1.2$ at group $A$ (normal healthy male secondary school students); while it was $20.60 \pm 1.2$ at group B (male secondary school students are suffering from flat foot).

Left Knee: There was statistically significant increase in participant's $Q$-angle $(P=0.05)$, as the mean value of $Q$-angle was $17.030 \pm 0.4$ group $A$ (normal healthy male secondary school students), while it was $22.4^{\circ} \pm 1.5$ at group $B$ (male secondary school students are suffering from flat foot) (Table I).

There were no statistically significant differences in the participant's quadriceps-angle between the right and left knee ( $P>0.05)$ at group A (normal healthy male secondary school students).

There were no statistically significant differences in the participant's quadriceps-angle between the right and left knee $(P>0.05)$ at group $B$ (male secondary school students are suffering from flat foot).

Table 1: Mean \pm SD values of $Q$ angle for participants (normal healthy male secondary school students versus students are suffering from flat foot).

\begin{tabular}{|c|c|c|c|c|c|c|c|c|}
\hline & \multicolumn{5}{|c|}{ Right Knee } & \multicolumn{4}{c|}{ Left Knee } \\
\cline { 2 - 9 } & Mean & \pm SD & P.value & Significance & Mean & $\pm S D$ & P.Value & Significance \\
\hline $\begin{array}{c}\text { Normal healthy male } \\
\text { students }\end{array}$ & 16.140 & \pm 1.2 & 0.05 & $\mathrm{~S}$ & 17.030 & \pm 0.4 & 0.05 & $\mathrm{~S}$ \\
\hline $\begin{array}{c}\text { Students suffering } \\
\text { from flat foot }\end{array}$ & 20.60 & \pm 1.2 & - & - & 22.40 & \pm 1.5 & - & - \\
\hline
\end{tabular}

The feet are considered as an important part of our body. It supports not only the whole body weight but also bears several times of body weight when we are running or splitting [19].

Flat foot is one of the most common foot deformities in children that may lead to foot or ankle pain during walking. A flatfoot deformity is where the arch on the inside border of the foot is more flat than normal and the entire sole of the foot comes into complete or near complete contact with the ground [18].

If the foot biomechanically functions in constant pronation the entire leg undergoes excessive internal rotation. The internal rotatory stress or position of excessive internal rotation of the leg may result in several possible problems around the knee, including excessive angulation of the patellar tendon and excessive pressure of the lateral patellar facet. A pronated foot may be the result of a functional leg length inequality if the problem is asymmetrical.

This is because pronation of the foot can lower the ankle joint axis and result in a slight reduction in overall limb length. Lowering the arches 
also tenses the plantar ligaments and the plantar fascia. Prolonged stress on these structures can result in a cycle of microtears, pain and inflammation [14-16].

Poor foot alignment may cause pain at other body joints, for example excessive subtalar joint pronation has been thought to contribute to leg, knee and back pain [13 ].

Asymmetrical subtalar joint pronation lead to asymmetrical hip joint rotation (excessive lateral rotation than medial rotation) consequently pathological toe out gait and sacroiliac joint dysfunction $[14,15]$.

The purpose of this study was to determine the relationship between flatfoot and $Q$ Angle in male secondary school students.

Forty participants were included in this study divided into two groups, group A (20 normal healthy male secondary school students) while group B (20 male secondary school students are suffering from flat foot ); (age range $16-18$ years, weight $71.5 \pm 14.4 \mathrm{~kg}$, height $171.5 \pm 6.1 \mathrm{~cm}$, were selected randomly.

Our study proved that that there was statistically significant increase in participant's $Q$-angle of right knee $(P=0.05)$, as the mean value of $Q$ angle was $16.14{ }^{\circ} \pm 1.2$ at group $A$ (normal healthy male secondary school students); while it was $20.60^{\circ} \pm 1.2$ at group B (male secondary school students are suffering from flat foot).

There was statistically significant increase in participant's $Q$-angle of the Left Knee $(P=0.05)$, as the mean value of $Q$-angle was $17.03^{\circ} \pm 0.4$ group $A$ (normal healthy male secondary school students), while it was $22.4^{\circ} \pm 1.5$ at group $B$ (male secondary school students are suffering from flat foot). So there is significant relationship between $Q$ angle increasing and flat foot deformity.

There were no statistically significant differences in the participant's quadriceps-angle between the right and left knee $(P>0.05)$ at group $A$ (normal healthy male secondary school students) and group B (male secondary school students are suffering from flat foot).

Our results matched with another study done by Amir Letafatkar et al, 2013 (17), the aim of this study was the surveying of Relationship between flat foot deformity with $Q$ angle and Int J Physiother Res 2017;5(6):2477-81. ISSN 2321-1822 knee pain in Iranian freestyle wrestlers.

The results of this study indicated that there is significant relationship between flat foot deformity and knee pain in wrestlers $(r=0.686)$. There is significant relationship between $Q$ angle increasing in dominant leg and knee pain $(r=0.949)$. Also there is significant relationship between $Q$ angle increasing in dominant leg and flat foot deformity ( $r=0.278)$.

\section{CONCLUSION}

With regard to this study results, we concluded that, flat foot deformity may resulted in increasing $Q$ angle.

\section{ACKNOWLEDGEMENTS}

To Allah, Ai-mighty God, asking him to accept my humble efforts as a good deed in the Day of Judgment and make it useful knowledge for all those who read it. To my dear Delta University for Science and Technology for their effort to support me to apply scientific research which useful to our society according to our environmental needs. I am obliged to thank all children that were involved in this thesis wishing them and their parents all cure and wellbeing.

\section{Conflicts of interest: None}

\section{REFERENCES}

[1]. A. M. Dowling, J. R. Steele. and L. A. Baur. Does obesity influence foot structure and plantar pressure patterns in prepubescent children? Int J Obese. 2001;25:845-852.

[2]. M. H. Jahss. Disorders of the foot. Philadelphia: WB Saunders Company, 1982.

[3]. R.F. Ker, et al. The spring in the arch of the human foot. Nature. 1987;325:14 -149.

[4]. M.A. Smith. Flat feet in children. BMJ. 1990;301:1331.

[5]. Kids' flat feet are normal. USA Today Magazine. 1991;119(2549):6-5.

[6]. A. García-Rodríguez, et al. Flexible flat feet in children: A real problem? Pediatrics. 1999;103: 84-89.

[7]. Cote KP, Brunet ME, Gansneder BM, Shultz SJ. Effects of Pronated and Supinated Foot Postures on Static and Dynamic Postural Stability. J Athl Train 2005;40:41-46.

[8]. Hertel J, H Jennifer, A Braham (2004) Lower extremity malalignment and anterior cruciate ligament injury history. Journal of Sports Science and Medicine, 2004;3:220-225.

[9]. Hertel J, Gay MR, Denegar CR. Differences in Postural Control During Single-Leg Stance Among Healthy Individuals With Different Foot Types. J Athl Train 2002;37:129-132. 
[10]. Tsai LC, Yu B, Mercer VS, Gross MT. Comparison of different structural foot types for measures of standing postural control. J Orthop Sports Phys Ther. 2006;36:942-953.

[11]. Williams DS 3rd, McClay IS, Hamill J. Arch structure and injury patterns in runners. Clin Biomech (Bristol, Avon)20001;16:341-347.

[12]. Livingston LA. The quadriceps angle: a review of the literature. J Orthop Sports Phys Ther. 1998;28:1059.

[13]. Cobb SC, Tis LL, Johnson BF, Higbie EJ. The effect of forefoot varus on postural stability. J Orthop Sports Phys Ther 2004;34:79-85.

[14]. Page P, Rouge B, Frank C. Assessment and treatment of muscle imbalances; Janda approach. Human Kinetics, 1st edn. 2010;70-142.

[15]. Richardson C, P Hodges, J Hides Therapeutic Exercise for Lumbopelvic Stabilization: A Motor Control Approach for the Treatment and Prevention of Low Back Pain, edn 2. Churchill Livingstone, Edinburgh. 2004.
[16]. Cote KP, Brunet ME, Gansneder BM, Shultz SJ. Effects of Pronated and Supinated Foot Postures on Static and Dynamic Postural Stability. J Athl Train 2005;40:41-46.

[17]. Amir Letafatkar, Shahrzad Zandi , Majid Khodayi and Jafar Belali Vashmesara. Flat Foot Deformity, Q Angle and Knee Pain are Interrelated in Wrestlers, J Nov Physiother 2013;3:2

[18]. Lovet, H.W., Dane, J. The affections of the arch of the foot commonly classified as flat-foot, The Jour-nal of Bone \& Joint Surgery:1986;78-92.

[19]. Woodburn J,Helliwell PS . Relation between heel position and the distribuation of fore foot plantar pressure and skin callosities in rhumatoid arthritis .Annals of rheumatic disorders .1996;55:806810 .

How to cite this article:

Mohamed N. AlKhouli, Anees S. Ghait, Amr A.Abogazya. RELATIONSHIP

BETWEEN FLATFOOT AND Q ANGLE IN MALE SECONDARY SCHOOL

STUDENTS. Int J Physiother Res 2017;5(6):2477-2481. DOI: 10.16965/ ijpr.2017.232 